\title{
Spontaneous migration of an implanted central venous access device into the ipsilateral jugular vein
}

\author{
Brett L. Houston MD, Matthew Yan MD
}

Competing interests: None declared.

This article has been peer reviewed.

The authors have obtained patient consent.

Affiliations: Department of Medicine (Houston), Division of Medical Oncology and Hematology, Department of Medicine (Yan), University of Toronto, Toronto, Ont.

Acknowledgement: The authors thank Dr. Richard Ward for facilitating the patient encounter and his assistance in reviewing the manuscript.

Correspondence to: Matthew Yan, Matthew. Yan@uhn.ca

CMAJ 2016. DOI:10.1503 /cmaj.150872
$\Delta$ 46-year-old man with sickle cell disease was assessed in our outpatient clinic for right neck pain. To facilitate venous access for manual exchange transfusions and iron chelation therapy, a central venous access device had been inserted into his right internal jugular vein by an interventional radiologist about 10 months prior. Its position in the upper right atrium had been confirmed by fluoroscopy (Appendix 1, available at www.cmaj.ca/ lookup/suppl/doi:10.1503/cmaj.150872/-/DC1).

Our patient described a five-day history of neck pain and aural fullness, after noting transient neck swelling with his exchange transfusion two weeks prior. He mentioned that he weight-lifted regularly, and his routine included bench-pressing $63 \mathrm{~kg}$, usually 100 repetitions three times weekly. Symptoms consistent with neurologic sequelae, infection or thrombosis were absent. Physical examination identified a palpable catheter within the right neck, deep to the sternocleidomastoid muscle. Chest radiography confirmed interval migration of the catheter tip from the upper right atrium to the right internal jugular vein (Figure 1). After fluoroscopic assessment, the catheter was removed by interventional radiology with reimplantation of a left-sided device.

Implanted central venous access devices can be critical to the care of patients with chronic disease, facilitating venous access for intermittent therapy, such as chemotherapy or transfusion support. The incidence of device use is increasing, with more than 200000 port insertions in the United States annually. ${ }^{1}$ However, venous access devices are not without risk. Spontaneous migration of these devices has an estimated incidence of $0.1 \%-1.8 \%$, typically presenting with neck or shoulder pain, venous phlebitis or thrombosis. ${ }^{2-4}$ Proposed mechanisms for migration include forced flushing, vigorous upper extremity move-

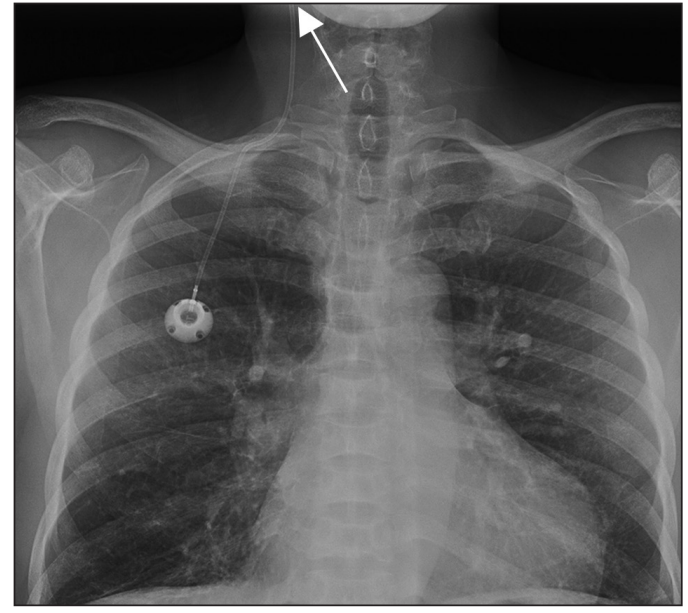

Figure 1: Posteroanterior chest radiograph showing the catheter tip (arrow) of an implantable central venous access device in the right internal jugular vein of a 46-year-old man with sickle cell disease.

ments, and abrupt changes in intrathoracic pressure secondary to vomiting or coughing. ${ }^{5}$ Our patient's overhead weight-lifting was a plausible explanation for his catheter migration, and we suggested that he modify his exercise routine accordingly.

\section{References}

1. Walser EM. Venous access ports: indications, implantation technique, follow-up, and complications. Cardiovasc Intervent Radiol 2012;35:751-64.

2. An H, Ryu CG, Jung EJ, et al. Insertion of totally implantable central venous access devices by surgeons. Ann Coloproctol 2015; 31:63-7.

3. Poorter RL, Lauw FN, Bemelman WA, et al. Complications of an implantable venous access device (Port-a-Cath) during intermittent continuous infusion of chemotherapy. Eur J Cancer 1996; 32A:2262-6.

4. Wu PY, Yeh YC, Huang CH, et al. Spontaneous migration of a Port-a-Cath catheter into ipsilateral jugular vein in two patients with severe cough. Ann Vasc Surg 2005;19:734-6.

5. Binnebösel M, Grommes J, Junge K, et al. Internal jugular vein thrombosis presenting as a painful neck mass due to a spontaneous dislocated subclavian port catheter as long-term complication: a case report. Cases J 2009;2:7991. 